\title{
Cytokine-driven Proliferation and Differentiation of Human Naive, Central Memory, and Effector Memory CD4 ${ }^{+} \mathrm{T}$ Cells
}

\author{
Jens Geginat, Federica Sallusto, and Antonio Lanzavecchia
}

Institute for Research in Biomedicine, Bellinzona 6500, Switzerland

\begin{abstract}
Memory $\mathrm{T}$ lymphocytes proliferate in vivo in the absence of antigen maintaining a pool of central memory $\mathrm{T}$ cells $\left(\mathrm{T}_{\mathrm{CM}}\right)$ and effector memory $\mathrm{T}$ cells $\left(\mathrm{T}_{\mathrm{EM}}\right)$ with distinct effector function and homing capacity. We compared human $\mathrm{CD}^{+}$naive $\mathrm{T}, \mathrm{T}_{\mathrm{CM}}$, and $\mathrm{T}_{\mathrm{EM}}$ cells for their capacity to proliferate in response to cytokines, that have been implicated in $\mathrm{T}$ cell homeostasis. Interleukin (IL)-7 and IL-15 expanded with very high efficiency $\mathrm{T}_{\mathrm{EM}}$, while $\mathrm{T}_{\mathrm{CM}}$ were less responsive and naive T cells failed to respond. Dendritic cells (DCs) and DC-derived cytokines allowed naive $\mathrm{T}$ cells to proliferate selectively in response to IL-4, and potently boosted the response of $\mathrm{T}_{\mathrm{CM}}$ to IL-7 and IL-15 by increasing the expression of the IL-2/IL-15R $\beta$ and the common $\gamma$ chain $(\gamma c)$. The extracellular signal regulated kinase and the p38 mitogen-activated protein (MAP) kinases were selectively required for TCR and cytokine-driven proliferation, respectively. Importantly, in cytokine-driven cultures, some of the proliferating $\mathrm{T}_{\mathrm{CM}}$ differentiated to $\mathrm{T}_{\mathrm{EM}^{-}}$-like cells acquiring effector function and switching chemokine receptor expression from CCR7 to CCR5. The sustained antigen-independent generation of $\mathrm{T}_{\mathrm{EM}}$ from a pool of $\mathrm{T}_{\mathrm{CM}}$ cells provides a plausible mechanism for the maintenance of a polyclonal and functionally diverse repertoire of human $\mathrm{CD} 4^{+}$memory $\mathrm{T}$ cells.
\end{abstract}

Key words: human $\mathrm{CD}^{+} \mathrm{T}$ cell subsets $\bullet$ memory maintenance $\bullet$ cytokines $\bullet$ differentiation $\bullet$ proliferation

\section{Introduction}

Naive and memory $\mathrm{T}$ lymphocyte numbers are maintained constant in adult animals to ensure that the organism can mount an immune response to a variety of new antigens, while keeping appropriate levels of memory cells to previously encountered pathogens (1-3). In intact animals naive $\mathrm{T}$ cells divide very slowly, while memory cells have a higher rate of division (4). Furthermore, in T cell-deficient mice transferred naive $\mathrm{T}$ cells rapidly proliferate in the $\mathrm{ab}-$ sence of antigen to reconstitute the lymphocyte pool while undergoing a limited differentiation process (5-8).

Signaling from the TCR and cytokine receptors have been implicated in the maintenance and homeostatic expansion of $\mathrm{T}$ cell pools, but their relative contribution may vary under different conditions. In particular, it has been shown that naive $\mathrm{CD}^{+}$and $\mathrm{CD} 8^{+} \mathrm{T}$ cells need to interact with self-MHC molecules in order to survive and proliferate under lymphopenic conditions, while memory $\mathrm{T}$ cells show no such requirement (9-15). The peptide ligands bound to self-MHC molecules responsible for positive selection in the thymus are also involved in $\mathrm{T}$ cell survival

Address correspondence to J. Geginat, Institute for Research in Biomedicine, Via Vela 6, Bellinzona 6500, Switzerland. Phone: 41-91-8200-342; Fax: 41-91-8200-302; E-mail: jens.geginat@irb.unisi.ch and homeostatic proliferation in the periphery (16-18). Two recent studies, however, argue that TCR tickling and p56Lck are required primarily for $\mathrm{T}$ cell expansion in lymphopenic hosts rather than for long-term survival $(19,20)$.

There is growing evidence that cytokines, which bind to receptors containing $\gamma c$, namely IL-2, IL-4, IL-7, and IL-15 (referred to thereafter as $\gamma$ c-cytokines), are involved in $\mathrm{T}$ cell maintenance and homeostasis. Indeed, $\gamma$ c-deficient mice show impaired $\mathrm{T}$ cell survival and homeostasis but normal proliferative response to antigenic stimulation (21, $22)$. The relative importance of different $\gamma c$-cytokines varies depending on their site of production and to the expression and signaling capacity of the relevant cytokine receptors on $\mathrm{T}$ cells. Pioneering studies using cytokine combinations containing IL-2, IL-6, and TNF- $\alpha$ showed that human $\mathrm{T}$ cells can proliferate in an antigen-independent manner in vitro $(23,24)$. IL-15, which is produced by several cell types including dendritic cells (DC)*s, plays an essential role in $\mathrm{T}$ cell homeostasis. IL-15 expands $\mathrm{CD}^{+}$

\footnotetext{
*Abbreviations used in this paper: CsA, Cyclosporin A; DC, dendritic cell; ERK, extracellular signal regulated kinase; JAK, Janus kinase; L, ligand; MAP, mitogen-activated protein; $\mathrm{T}_{\mathrm{CM}}$, central memory $\mathrm{T}$ cell; $\mathrm{T}_{\mathrm{EM}}$, effector memory $\mathrm{T}$ cell; TSST, toxic shock syndrome toxin.
} 
memory $\mathrm{T}$ cells in vivo $(25,26)$ and deletion of IL-15R $\alpha$ results in reduced numbers of CD8 memory cells (27). The effects of IL-15 can be counteracted by IL-2, which primes mouse $\mathrm{T}$ cells for death, suggesting that CD8 homeostasis might be regulated at the level of these two opposing cytokines (28). IL-7, which is produced by stromal cells, can enhance homeostatic proliferation of both naive and memory CD8 ${ }^{+} \mathrm{T}$ cells $(29)$. Furthermore, IL-7 and IL-4 contribute, together with self-MHC molecules, to naive $\mathrm{T}$ cell survival (30). In humans increased IL-7 expression is associated with enhanced $\mathrm{T}$ cell turnover in lymphopenic HIV patients (31).

It is well established that naive and memory cells have different capacities to traffic in lymphoid and nonlymphoid tissues (32). Recent evidence indicates that memory CD4 ${ }^{+}$ and $\mathrm{CD} 8^{+} \mathrm{T}$ cells comprise at least two functionally distinct subsets: (i) nonpolarized "central memory" $\mathrm{T}$ cells $\left(\mathrm{T}_{\mathrm{CM}}\right)$, which express the chemokine receptor CCR7 and CD62 ligand (L) and home to the T cell areas of secondary lymphoid organs; and (ii) polarized "effector memory" T cells $\left(\mathrm{T}_{\mathrm{EM}}\right)$, which have lost the expression of CCR7 and have acquired the capacity to migrate to nonlymphoid tissues (33-37). These findings suggest that $T_{C M}$ and $T_{E M}$ have access to different environments and possibly different survival stimuli. It is possible that in the $\mathrm{T}$ cell differentiation program cytokine receptor expression might be coordinately regulated with migratory capacity and effector function. However, the responsiveness of naive and memory $\mathrm{T}$ cell subsets to cytokines has not been investigated.

In this work we describe the selective expansion of naive $\mathrm{T}$ and memory subsets using different combinations of $\gamma \mathrm{c}-$ and DC-derived cytokines and define distinct signaling requirements for TCR-versus cytokine-driven proliferation. We also show that cytokine-driven $\mathrm{T}_{\mathrm{CM}}$ but not naive $\mathrm{T}$ cells differentiate acquiring effector function and switching expression of chemokine receptors. The sustained antigenindependent generation of $\mathrm{T}_{\mathrm{EM}}$ from a pool of $\mathrm{T}_{\mathrm{CM}}$ cells provides a plausible mechanism for the maintenance of a polyclonal and functionally diverse repertoire of human $\mathrm{CD} 4^{+}$memory $\mathrm{T}$ cells.

\section{Materials and Methods}

Antibodies and Reagents. Phycoerythrin (PE)-labeled antibodies specific for IL-6R $\alpha$, IL $2 R \alpha$, IL-2/15R $\beta$, IL-4R $\alpha$, CD40L, and CD45RA were purchased from Beckman Coulter. Antiphospho-p38 antibodies were purchased from Southern Biotechnology and anti-phospho-extracellular signal regulated kinase (ERK) from Sigma-Aldrich. All recombinant cytokines (IL-1 $\beta$, IL-2, IL-4, IL-6, IL-7, IL-10, IL-12, IL-15, TNF- $\alpha$ ) and antibodies to IL-4, IFN- $\gamma$, MHC class II, CCR 5, IL-10R and the $\gamma c$-chain were purchased from BD PharMingen. The antiCCR7 antibody (3D12) was provided by M. Lipp, Max-Deebrueck Center for Molecular Medicine, Berlin, Germany. The signaling inhibitors were purchased from Alexis and used as follows: the src tyrosine kinase inhibitor PP2 at $1 \mu \mathrm{M}$, the Janus kinase (JAK) 32 Inhibitor at $25 \mathrm{ng} / \mathrm{ml}$, Cyclosporin A (CsA) at 50 $\mathrm{nM}$, the PKC inhibitor bisindolylmaledeide at $1 \mu \mathrm{M}$, the PI3 Kinase inhibitor LY294002 at $10 \mu \mathrm{M}$, the MEK inhibitor
PD98059 at $50 \mu \mathrm{M}$ and the p38 inhibitors SB202190 and PD169316 at $10 \mu \mathrm{M}$.

Cell Culture. Peripheral blood mononuclear cells were isolated from healthy blood donors. B cells and monocytes were depleted by plastic adherence and passage through a nylon wool column. NK cells, $\mathrm{CD}^{+} \mathrm{T}$ cells, residual B cells and monocytes were depleted by panning technique with antibodies to CD8 (OKT8), CD14 (144), CD20 (HB9645), and CD16 (B73.1). The T cells obtained were $>97 \% \mathrm{CD}^{+}{ }^{+} \mathrm{CD}^{+}$. Naive and memory $\mathrm{T}$ cell subpopulations were purified to $>99 \%$ by cell sorting, using anti-CD4 in combination with anti-CD45RO and anti-CCR7 $\mathrm{Ab}$ (33). Labeling of $\mathrm{T}$ cells with CFSE (Molecular Probes) was performed as described previously (38). DCs were purified by positive selection with anti-CD14 antibodies coupled to magnetic beads (Miltenyi Biotec). CD14 ${ }^{+}$cells were cultured for $5 \mathrm{~d}$ in RPMI 1640 containing $2 \mathrm{mM}$ glutamine, $1 \%$ nonessential amino acids, $1 \%$ sodium pyruvate, $50 \mu \mathrm{g} / \mathrm{ml}$ kanamycin (GIBCO BRL), 1\% human serum, $50 \mathrm{ng} / \mathrm{ml}$ GM-CSF (Novartis), and $1,000 \mathrm{U} / \mathrm{ml} \mathrm{IL}-4$. The DCs obtained were stimulated with $100 \mathrm{ng} / \mathrm{ml}$ LPS where indicated (from Salmonella abortus equi; Sigma-Aldrich). T cells were cultured with DCs at a 5:1 ratio. In some experiments DCs were pulsed with $100 \mathrm{ng} / \mathrm{ml}$ toxic shock syndrome toxin (TSST; Toxin Technologies). All recombinant cytokines were used in culture at $25 \mathrm{ng} / \mathrm{ml}$. For inhibition experiments, $\mathrm{T}$ cells were preincubated with the various inhibitors for $30 \mathrm{~min}$ and the inhibitors were left in culture for the entire stimulation period.

FACS ${ }^{\circledR}$ Analysis. Cell staining of CFSE-labeled T cells were performed with APC- or PE-labeled antibodies with the exception of the anti-CCR7 Ab, which was detected with a PElabeled anti-rat antibody (BD PharMingen). Cells were analyzed on a FACSCalibur ${ }^{\mathrm{TM}}$ (Becton Dickinson). Effector cytokine producing capacity was assessed after stimulation for $6 \mathrm{~h}$ with 100 $\mathrm{nM}$ PMA and $1 \mu \mathrm{g} / \mathrm{ml}$ Ionomycin (Sigma-Aldrich). Brefeldin A (Sigma-Aldrich) was added at $10 \mu \mathrm{g} / \mathrm{ml}$ during the last $4 \mathrm{~h}$ of stimulation. Cells were fixed with $2 \%$ paraformaldehyde, permeabilized with PBS containing 10\% FCS, and 0.5\% saponin followed by staining with APC-labeled anti-IFN- $\gamma$ and PE-labeled anti-IL-4 antibodies.

Immunoblotting. Cell lysates (Tris-Cl $50 \mathrm{mM}, \mathrm{pH} 7.4, \mathrm{NP}-$ $400.5 \%, 0.15 \mathrm{M} \mathrm{NaCl}, 2 \mathrm{mM}$ EDTA, $10 \mathrm{mM} \mathrm{NaF}, 10 \mathrm{mM}$ $\mathrm{P}_{2} 0_{7}, 0.5 \mu \mathrm{M} \mathrm{Na} \mathrm{VO}_{4}, 100 \mu \mathrm{g} / \mathrm{ml}$ PMSF, $1 \mu \mathrm{g} / \mathrm{ml}$ aprotinin and leupeptin) were cleared by centrifugation, boiled in sample buffer, and resolved on a 10\% SDS-PAGE. Proteins were transferred on a nitrocellulose membrane (Amersham Pharmacia Biotech). Incubations with primary and secondary, horseradish peroxidase-conjugated antibodies were performed in blocking buffer (5\% dry nonfat milk in Tris buffered saline, $\mathrm{pH} 7.4$, containing $0.05 \%$ Tween 20 (TBST) while the antiphospho-p38 antibody was diluted in 5\% BSA in TBST. Blots were developed with an ECL kit (Amersham Pharmacia Biotech).

RNase Protection Assay. Lysis and RNA isolation from $2-5 \times$ $10^{6}$ cells was performed with the RNeasy kit (QIAGEN). The anti-sense mRNA probes of the human cytokine receptors template set hCR-1 (Riboquant; BD PharMingen) were labeled with ${ }^{32}[\mathrm{P}]$ using the Maxiscript kit (QIAGEN). The probe was purified with a G50 mini-column (Amersham Pharmacia Biotech). Hybridization of $2.5-5 \mu \mathrm{g}$ RNA with $3 \times 10^{5} \mathrm{cpm}$ probe and RNase digestion was performed with the HybSpeed kit (Ambion). Undigested RNA was precipitated and loaded on a 5\% denaturating acrylamide gel, run for $2.5 \mathrm{~h}$ at $400 \mathrm{~V}$, dried, and exposed to a film. 


\section{Results}

T Cell Proliferation In Response to TCR or Cytokine Stimulation. Based on previous reports $(23,24)$ and preliminary experiments, we defined a cytokine combination that efficiently drives proliferation of human peripheral blood $\mathrm{T}$ lymphocytes. Using the CFSE dilution method to track cell division (38), we compared the proliferative response of naive $\mathrm{CD}^{+} \mathrm{T}$ cells to either cytokines or antigenic stimulation (Fig. 1). As expected, stimulation of naive $\mathrm{T}$ cells with DCs pulsed with the bacterial superantigen TSST induced the rapid outgrowth of a small fraction $(\sim 5 \%)$ of $\mathrm{V} \beta 2^{+}$cells. The first division occurred after a lag period of $\sim 40 \mathrm{~h}$ and cells subsequently divided rapidly, approximately every $10 \mathrm{~h}$. In contrast, when exposed to a combination of IL-7, IL-15, TNF- $\alpha$, IL-6, and IL-10, all T cells divided, although with a slower kinetics: the first division occurred after $\sim 72 \mathrm{~h}$ and the division time was $\sim 30 \mathrm{~h}$.

DCs Prime Naive $T$ Cells to Respond to $\gamma$ c-Cytokines. When cultured with IL-7 and IL-15, memory CD4 ${ }^{+} \mathrm{T}$ cells (comprising both $\mathrm{T}_{\mathrm{CM}}$ and $\mathrm{T}_{\mathrm{EM}}$ ) proliferated extensively, while naive $\mathrm{T}$ cells failed to do so (Fig. 2 A). Because naive $\mathrm{T}$ cells traffic to the $\mathrm{T}$ cell areas of secondary lymphoid organs and make extensive contacts with DCs, we tested whether DCs may synergize with $\gamma$ c-cytokines
A

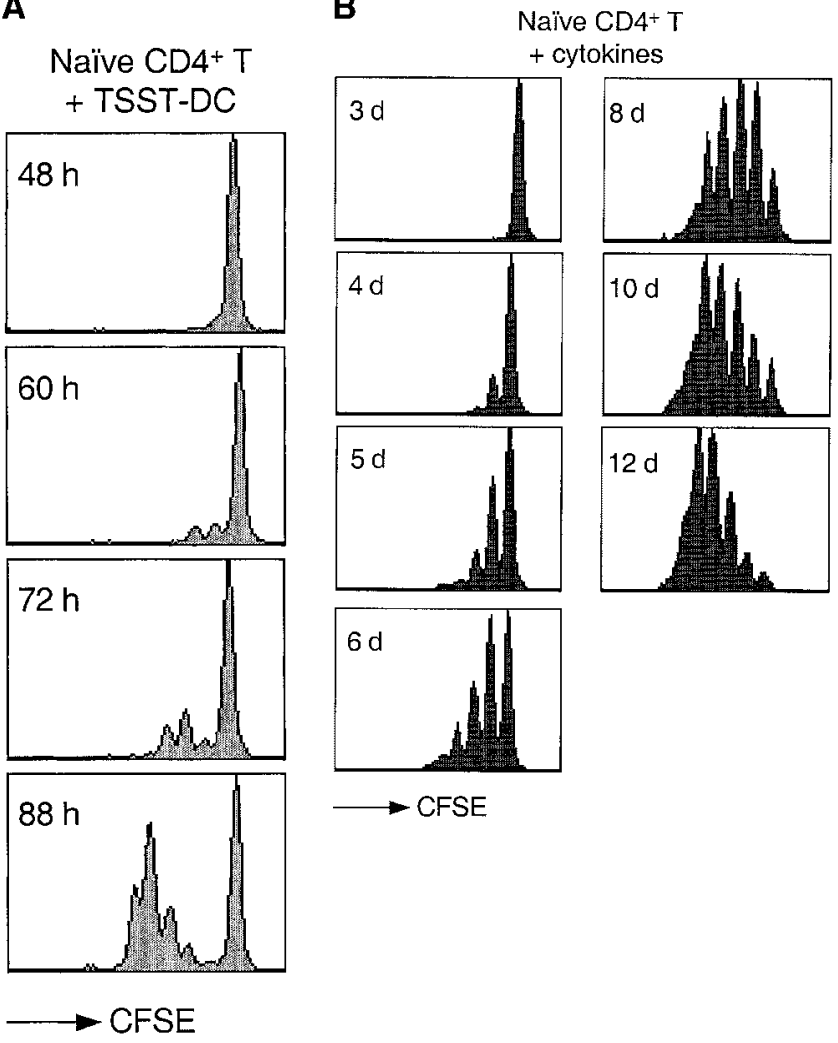

Figure 1. Kinetics of TCR- and cytokine-induced $\mathrm{T}$ cell proliferation. CFSE-labeled naive $\mathrm{CD}^{+} \mathrm{T}$ cells were stimulated with either TSSTloaded autologous DCs (A) or with a cytokine mixture (IL-7, IL-15, TNF- $\alpha$, IL-6, and IL-10) (B). Cell division was measured by flow cytometry at the time indicated. and polyclonally expand naive T cells (Fig. 2 A). Autologous DCs did not induce polyclonal $\mathrm{T}$ cell proliferation (data not shown), but endowed all naive $\mathrm{T}$ cells with the capacity to respond to IL-15 and IL-7 and enhanced responsiveness of memory $\mathrm{T}$ cells. The effect of DCs on cytokine-driven $\mathrm{T}$ cell proliferation was not inhibited by addition of antibodies to MHC class II molecules, suggesting that the latter were not involved in this process. The cellfree supernatant of LPS-stimulated, but not of unstimulated DCs had a similar effect as live DCs, since it did not induce proliferation on its own (data not shown), but enhanced responsiveness to IL-7 and IL-15. These results suggest that DC-derived, maturation-induced soluble factors were responsible for the observed effects.

Selective Expansion of Naive, $T_{C M}$, and $T_{E M} C D 4^{+}$Cell Subsets. $\mathrm{CD}^{+}$naive, $\mathrm{T}_{\mathrm{CM}}$, and $\mathrm{T}_{\mathrm{EM}}$ cells were isolated by cell sorting from peripheral blood according to expression of CD45RA and CCR7 and tested for their proliferative response to cytokines (Fig. 2 B). Three observations were
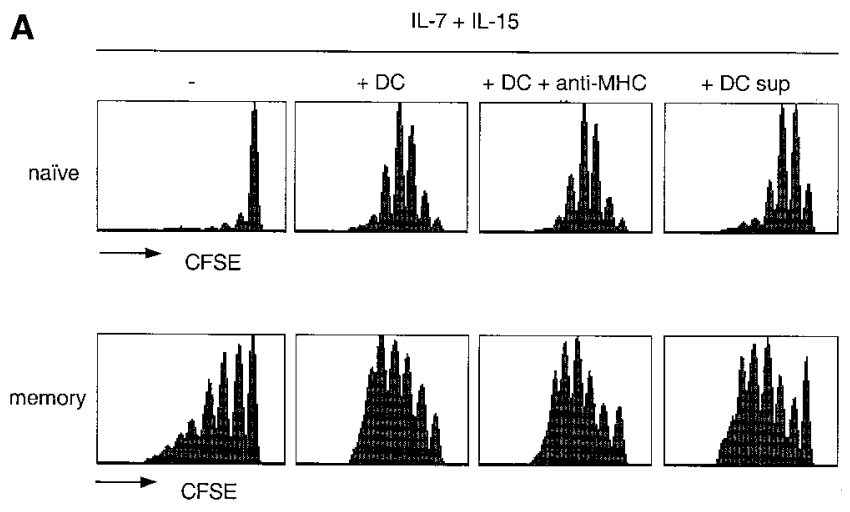

B

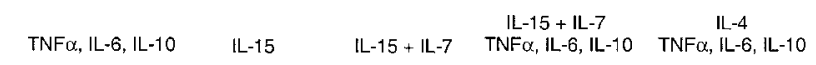

$T_{N}$

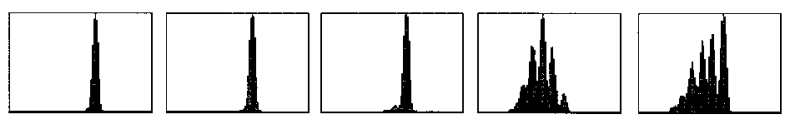

$T_{C M}$
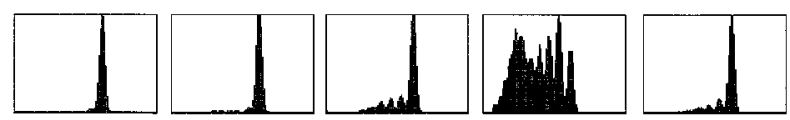

$T_{\mathrm{EM}}$
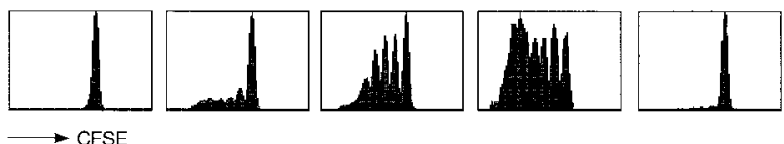

Figure 2. Differential requirements for cytokine-induced proliferation of naive $\mathrm{T}, \mathrm{T}_{\mathrm{CM}}$, and $\mathrm{T}_{\mathrm{EM}}$ cell subsets. (A) CFSE-labeled naive and memory $\mathrm{CD}^{+} \mathrm{T}$ cells were cultured for $7 \mathrm{~d}$ with IL-7 and IL-15 alone or in combination with autologous DCs, in the absence or presence of a blocking anti-MHC class II antibody, or with the supernatant of 24-h LPSactivated DCs. (B) $\mathrm{CD}^{+}$naive, $\mathrm{T}_{\mathrm{CM}}$, and $\mathrm{T}_{\mathrm{EM}}$ cells were isolated by cell sorting from peripheral blood according to their expression of CD45RA and CCR7. CFSE-labeled cells were cultured in the presence of different cytokines as indicated. Cell division was assessed by flow cytometry after $7 \mathrm{~d}$. One representative experiment out of five and eight, respectively. 
made. First, IL-7, which was poorly mitogenic on its own (data not shown), synergized with IL-15 in driving proliferation of $\mathrm{T}_{\mathrm{EM}}$, had a modest effect on $\mathrm{T}_{\mathrm{CM}}$, and no effect on naive $\mathrm{T}$ cells. Second, a mixture of TNF- $\alpha$, IL-6, and IL-10 could substitute for DCs. These cytokines, that alone did not induce proliferation of either naive or memory cells, enhanced IL-7 plus IL-15-driven proliferation of all subsets tested. Third, IL-4, which by itself was not effective (data not shown), in combination with DC-derived cytokines selectively induced proliferation of naive but not memory cells. Taken together these results identify two groups of cytokines: (i) $\gamma \mathrm{c}$-cytokines, that drive $\mathrm{T}$ cell proliferation; and (ii) DC-derived cytokines that prime naive $\mathrm{T}$ and $\mathrm{T}_{\mathrm{CM}}$ cells to respond to $\gamma \mathrm{c}$-cytokines. They also show that using appropriate cytokine combinations naive and memory $\mathrm{T}$ cell subsets can be selectively expanded.

Cytokine Receptor Expression and Regulation in Naive and Memory T Cell Subsets. The differential requirement for DC-derived cytokines and the differential responsiveness to IL-4 and IL-15 suggest that naive and memory T cells express different receptors for these cytokines. As shown in Fig. 3, the IL-2/IL-15R $\beta$-chain was expressed at very low levels on naive cells, at intermediate levels on $\mathrm{T}_{\mathrm{CM}}$ and at high levels on $\mathrm{T}_{\mathrm{EM}}$. In each subset, DC-derived cytokines rapidly increased the expression of IL-2/IL-15R $\beta$ chain. However, the increase was most pronounced in naive $T$ cells, a result that is consistent with the increased proliferation to IL-15 induced by this treatment. The $\gamma \mathrm{c}$-chain was expressed at comparable levels on all three subsets and was also upregulated (3-4-fold) by DC-derived cytokines. Remarkably, the increase of both IL-2/IL-15R $\beta$ and $\gamma$ c-chain expression induced by DC-derived cytokines was compa- rable to that induced by TCR stimulation (data not shown). This indicates that the two pathways can independently confer responsiveness to $\gamma c$-cytokines. In contrast, CD25, which is required to respond to low doses of IL-2, was selectively upregulated by TCR stimulation but not by DC-derived cytokines (data not shown).

Receptors for DC-derived cytokines were differentially expressed, IL-6R $\alpha$ being present on naive and $T_{C M}$, but lost on $\mathrm{T}_{\mathrm{EM}}$, while IL-10R was retained and actually increased on $\mathrm{T}_{\mathrm{EM}}$ (Table I A). The differential expression of these receptors correlates with changes in the capacity to respond to individual cytokines, TNF- $\alpha$ and IL- 6 being the most effective for naive T cells, while IL-10 and IL-12 being most effective for $\mathrm{T}_{\mathrm{EM}}$ (Table I A). Naive and memory $\mathrm{T}$ cells expressed IL-7R $\alpha, \gamma \mathrm{c}$-chain and low levels of IL-4R $\alpha$ mRNAs (data not shown). Addition of IL-4 induced a marked upregulation of the IL-4R $\alpha$-chain on naive, but not on memory $\mathrm{T}$ cells both at the RNA (data not shown) and protein level (Fig. 3), explaining the selectivity of IL-4 as a growth factor for naive $\mathrm{CD}^{+} \mathrm{T}$ cells. However, since IL-4 downregulates $\gamma c$ (but not IL-2/15R $\beta$ ) chain selectively on naive $\mathrm{T}$ cells, their proliferation still requires the contribution of DC-derived cytokines for the upregulation of $\gamma c$ chain expression.

Altogether these data indicate that the enhancing effect of DC-derived cytokines on IL-7 and IL-15 induced proliferation is due to the upregulation of the IL-2/IL-15R $\beta$ and the $\gamma_{c}$ chains. In addition, the selective responsiveness of naive T cells to IL- 4 and of $\mathrm{T}_{\mathrm{EM}}$ to IL-15 can be related to the differential regulation of the corresponding receptors, which are respectively lost or acquired after $\mathrm{T}$ cell differentiation.
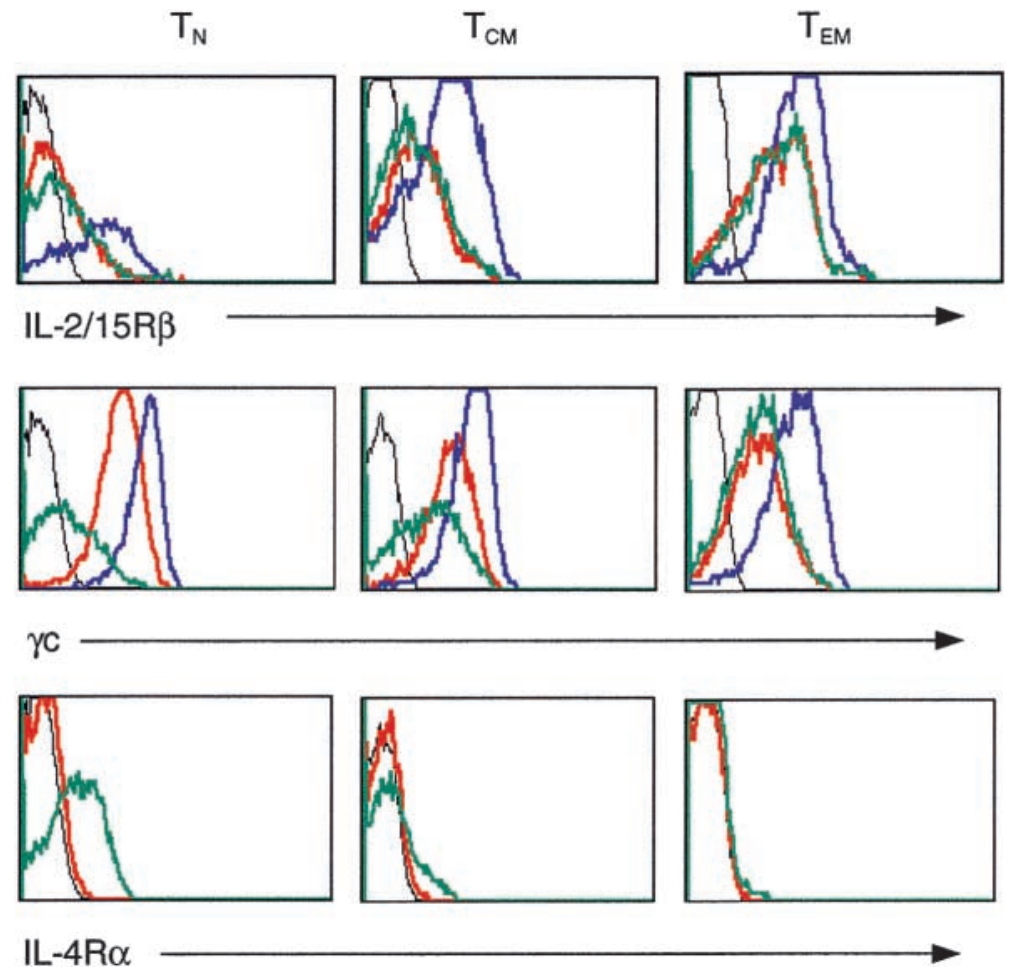

Figure 3. Modulation of cytokine receptors on $\mathrm{T}$ cell subsets by DC-derived cytokines or IL-4. Naive, $\mathrm{T}_{\mathrm{CM}}$, and $\mathrm{T}_{\mathrm{EM}}$ cells were cultured for $16 \mathrm{~h}$ in the absence (red) or in the presence of TNF- $\alpha$, IL- 6 , and IL-10 (blue) or IL-4 (green) and stained with antibodies to IL-2/IL-15R $\beta, \gamma c$ and IL-4R $\alpha$. The black lines show staining with isotypematched controls. One representative experiment out of five. 
Table I. Expression and Modulation of Cytokine Receptor Chains in $\mathrm{CD}^{+}$Naive and Memory T Cell Subsets

(A) Cytokine receptor surface expression $(\mathrm{MFI})^{\mathrm{a}}$

\begin{tabular}{lccl} 
& T naive & $\mathrm{T}_{\mathrm{CM}}$ & $\mathrm{T}_{\mathrm{EM}}$ \\
\hline IL-6R & 14 & 15 & 3 \\
IL-10R & $4(5)^{\mathrm{b}}$ & $7(13)^{\mathrm{b}}$ & $7(13)^{\mathrm{b}}$
\end{tabular}

(B) $\alpha c$ chain surface expression (fold-induction) ${ }^{c}$

$\begin{array}{llll}\text { TNF- } \alpha & 2.5 & 2 & 1.5 \\ \text { IL-6 } & 2 & 1.5 & 1 \\ \text { IL-10 } & 2 & 2 & 3.5 \\ \text { IL-12 } & 1.5 & 1.5 & 2.5 \\ \text { TNF- } \alpha+\text { IL-6 + IL-10 } & 4 & 3 & 4.5\end{array}$

${ }^{\text {a }}$ Unstimulated $\mathrm{T}$ cell subsets were stained with antibodies to IL-6R or IL-10R. Mean fluorescence index (MFI) after subtraction of the background is indicated.

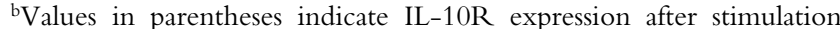
with IL-7 and IL-15 for $16 \mathrm{~h}$.

${ }^{\mathrm{c}} \mathrm{T}$ cell subsets were cultured as in Fig. 4 and analyzed after $16 \mathrm{~h}$ for surface expression of ac chain. The fold-increase in MFI after subtraction of the background is shown.

Distinct Signaling Requirements for Cytokine versus TCRdriven Proliferation. Because TCR and cytokine receptors engage mainly distinct, although partially, overlapping signaling pathways $(39,40)$ we investigated the effect of drugs that block signal transduction components on TCR-versus cytokine-driven proliferation (Fig. 4 A).

Inhibition of the downstream effectors of the PLC- $\gamma$ pathway with bisindolylmaledeide (BIM, a PKC inhibitor) or CsA (a calcineurin inhibitor) prevented TCR-induced proliferation. However, no detectable effect was observed on the cytokine-induced response, confirming that cytokine-induced proliferation is TCR-independent. Both TCR- and cytokine-driven proliferation are dependent on a $\mathrm{G} 1$ to $\mathrm{S}$ cell cycle transition induced by $\gamma$ c-cytokines. Indeed, inhibition of the $\gamma$ c-cytokine-dependent pathways, with a JAK3 inhibitor, with the TOR kinase inhibitor Rapamycin or with the PI3 kinase inhibitor LY294002, blocked both cytokine- and TCR-dependent proliferation. Interestingly, while Lck and ERK are activated after both TCR and cytokine stimulation $(41,42)$, the Lck and MEK1/2 inhibitors PP2 and PD98059 abrogated TCRinduced, but not cytokine-induced proliferation, suggesting that in the latter case these pathways are dispensable. Reciprocally, while the p38 mitogen-activated protein (MAP) kinase pathway is stimulated by both TCR and cytokines, its selective inhibition by PD169316 (data not shown) and SB202190 resulted in a selective block of cytokine-induced but not TCR-induced proliferation (Fig. 4 A). Importantly, p38 MAP kinase activity was required both in the absence and presence of DC-derived cytokines (data not shown).

According to the above results, ERK inhibition blocks TCR-dependent proliferation while p38 inhibition blocks cytokine-dependent proliferation. Therefore, we compared the activation profiles of these MAP kinases in cytokine- versus TCR-stimulated cells by immunoblotting with antibodies specific for the active form of the kinases. The ERK MAP kinase was strongly activated by TCR stimulation, and only weakly by cytokine stimulation. PD98059, which blocks the activating ERK-kinase MEK, prevented ERK phosphorylation in both cytokine- and

A
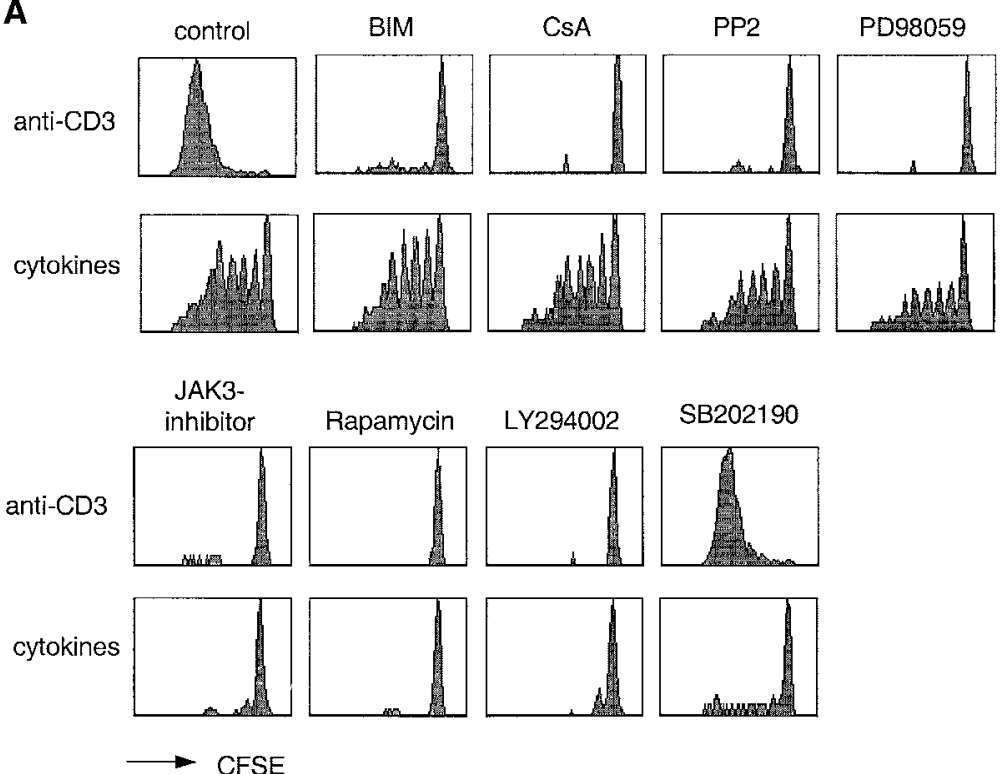

min in the presence or absence of inhibitors. ERK (B) and p38 (C) were assessed by immunoblotting with antibodies specific for the active kinases. Protein amount was controlled by reblotting with an antibody specific for total p38 (data not shown). One experiment out of four and three, respectively.

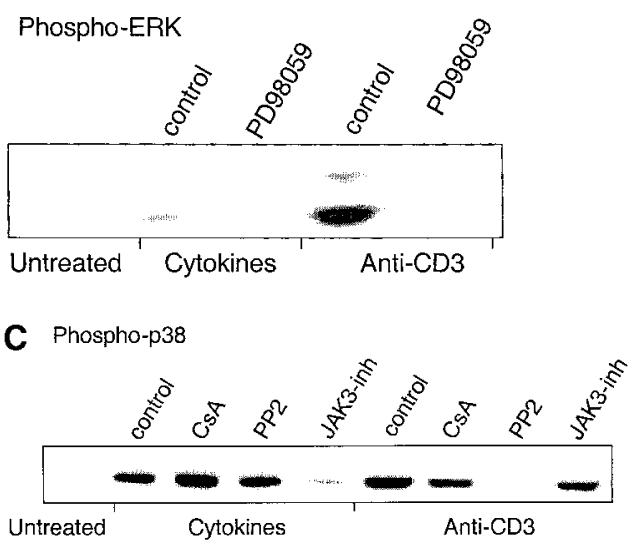

Figure 4. Differential requirements for signal transduction pathways in TCR- versus cytokine-driven proliferation. (A) CFSE-labeled $\mathrm{CD}^{+} \mathrm{T}$ cells were stimulated with platebound anti-CD3 or with cytokines (IL-7, IL-15, TNF- $\alpha$, IL-6, and IL-10) for $7 \mathrm{~d}$ in the absence (control) or in the presence of optimal concentrations of the indicated inhibitors. (B and C) $\mathrm{CD}^{+} \mathrm{T}$ cells were stimulated as above for 20 hoblotting with antibodies specific for the active kinases. Pro-
hown . Onperiment out of four and three, respectively. 
TCR-stimulated cells (Fig. 4 B). Furthermore, the p38 MAP kinase was activated by both TCR- and cytokinestimulation (Fig. 4 C). However, while TCR-dependent p38 activation was blocked by PP2 and partially by CsA, cytokine-dependent p38 activation was not affected by these drugs but was blocked by a JAK3 inhibitor. Altogether these findings indicate that the TCR and cytokine receptors activate p38 by different mechanisms and that p38 activation is required for cytokine-dependent, but not for TCR-dependent proliferation.

Cytokine-driven Differentiation of Naive and $T_{C M}$ Cells. Recent studies in the mouse system demonstrated that naive $\mathrm{T}$ cells transferred into lymphopenic mice expand and acquire some markers and functions of effector cells, but retain a partially naive/resting phenotype $(5-8)$. We therefore compared TCR- and cytokine-stimulated T cells for the expression of surface markers characteristic of activated/memory cells (Fig. 5). TCR-stimulated naive $\mathrm{T}$ cells upregulated CD40L and progressively downregulated CD45RA and CCR7 as a function of cell division. In contrast, cytokine-expanded naive $T$ cells maintained CCR7 expression and even upregulated CD45RA, while only a fraction of the cells upregulated CD40L. In response to the same treatment, $T_{C M}$ upregulated CD40L on a higher proportion of cells and to a higher level, while remaining CD45RA ${ }^{-}$. Importantly, while cytokine-stimulated naive $\mathrm{T}$ cells retained CCR 7 expression, $\mathrm{T}_{\mathrm{CM}}$ cells downregulated CCR 7 and upregulated CCR5, a chemokine receptor characteristic of effector $\mathrm{T}$ cells. Furthermore, a large fraction of cytokineexpanded $\mathrm{T}_{\mathrm{CM}}$ acquired the capacity to produce IFN- $\gamma$ (23\%) and IL-4 (13\%) (Fig. 6 A). In contrast, only a small fraction of naive $\mathrm{T}$ cells acquired effector function under the same culture conditions. Taken together these findings indicate that, upon cytokine stimulation, $\mathrm{T}_{\mathrm{CM}}$ (but not naive $\mathrm{T}$ cells) differentiate to $\mathrm{T}_{\mathrm{EM}}$-like cells with loss of lymph node homing capacity and acquisition of in- flamed tissue homing capacity as well as effector function.

IL-12 and IL-4 are the master cytokines that promote Th1 and Th2 polarization in TCR-stimulated cells. We investigated whether these polarizing cytokines might exert the same effect in $\mathrm{T}$ cells that proliferate in response to cytokines in the absence of TCR stimulation. Since T cell differentiation is influenced by division number and since both IL-4 and IL-12 had an enhancing effect on cytokinedriven proliferation (in the presence of DC-derived cytokines; data not shown), we analyzed IL-4 and IFN- $\gamma$ production on cells that had undergone the same number of divisions (Fig. 6 B). While IL-12 and IL-4 exerted the expected Th1 and Th2 polarizing effect in TCR-stimulated naive $T$ cells, their effects on cytokine-stimulated cells was surprisingly different. Indeed, under cytokine-driven conditions, IL-4 failed to induce Th2 polarization and even slightly enhanced Th polarization. Moreover, IL-12 not only enhanced Th1 but also Th2 polarization. Comparable results were obtained with $T_{C M}$ cells as well as with naive $T$ cells purified from cord blood. Addition of IL-7, IL-15, or of DC-derived cytokines did not change the polarizing effect of IL-4 and IL-12 on TCR-stimulated cells (data not shown). These results indicate that the effect of IL-12 and IL-4 on polarization depends on the activating stimulus e.g., TCR versus cytokines.

\section{Discussion}

The upregulation of cytokine receptors induced by TCR stimulation is the basis of antigen-driven clonal expansion, which is mediated by $\gamma$ c-cytokines produced by $\mathrm{T}$ cells in an autocrine fashion (43). We have shown here that DCs as well as DC-derived cytokines (TNF- $\alpha$, IL-6, IL10 , and IL-12) promote $\mathrm{T}$ cell proliferation in response to $\gamma c$-cytokines. Like TCR stimulation, DC-derived cytokines can upregulate IL-2/15R $\beta$ and $\gamma c$ chain expression

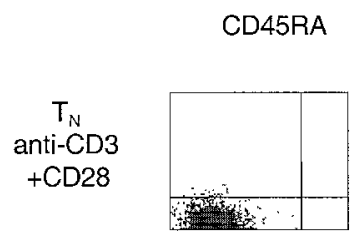

$\mathrm{CD} 40 \mathrm{~L}$
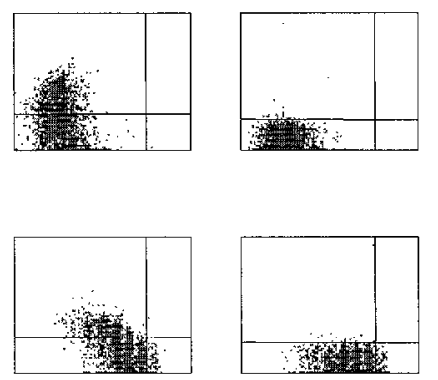

+cytokines
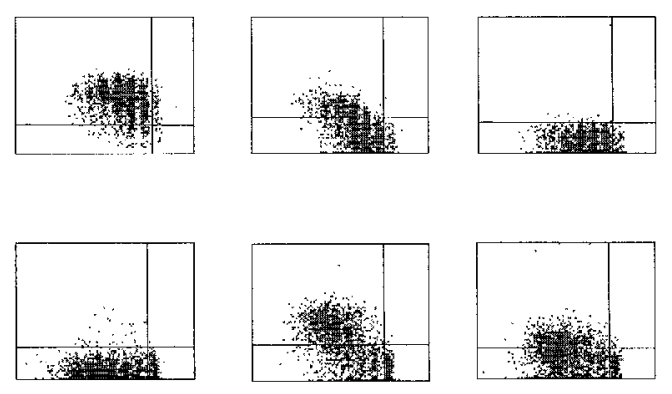
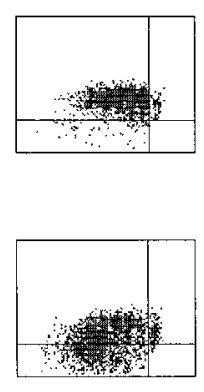

CCR7

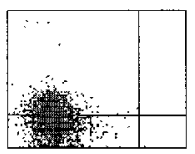

Figure 5. Cytokine expanded $\mathrm{T}_{\mathrm{CM}}$ differentiate and switch chemokine receptor expression. CFSE-labeled $\mathrm{CD}^{+}$naive $\mathrm{T}$ and $\mathrm{T}_{\mathrm{CM}}$ cells were stimulated with plate-bound anti-CD3 and anti-CD28 or with cytokines (IL-7, IL-15, TNF- $\alpha$, IL-6, IL-10) and stained after $7 \mathrm{~d}$ with antibodies specific for the indicated surface receptors (y axis, PE, or APC staining). One experiment out of five. 
A
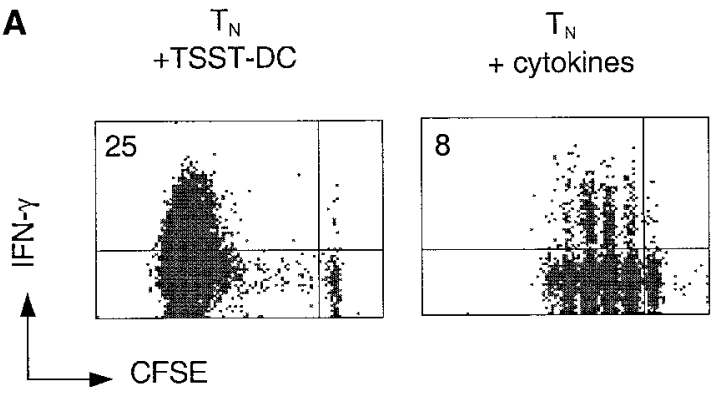

+ cytokines

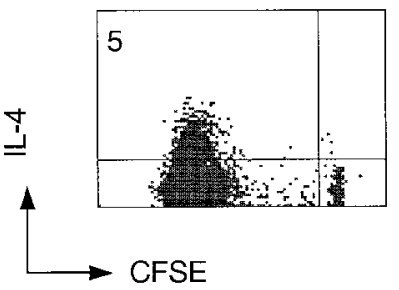

B
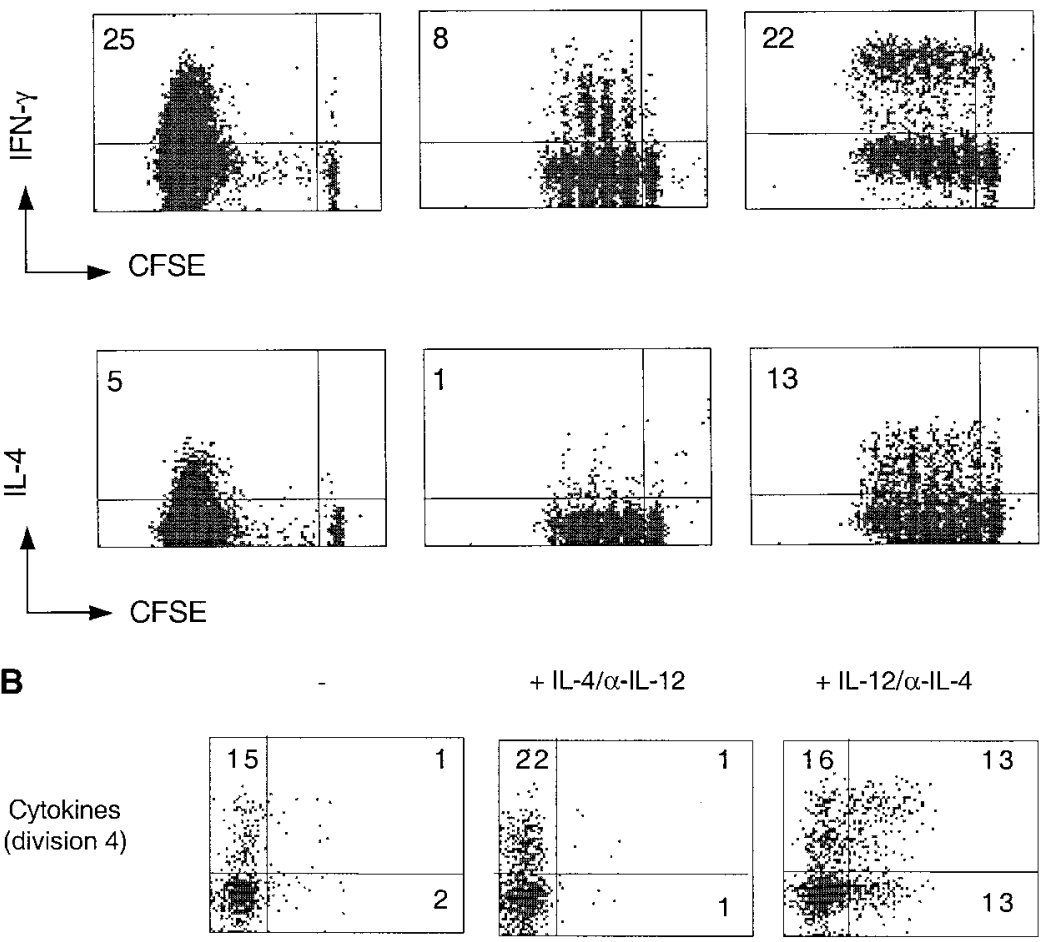

+ cytokines

$+\mathrm{IL}-4 / \alpha-\mathrm{IL}-12$
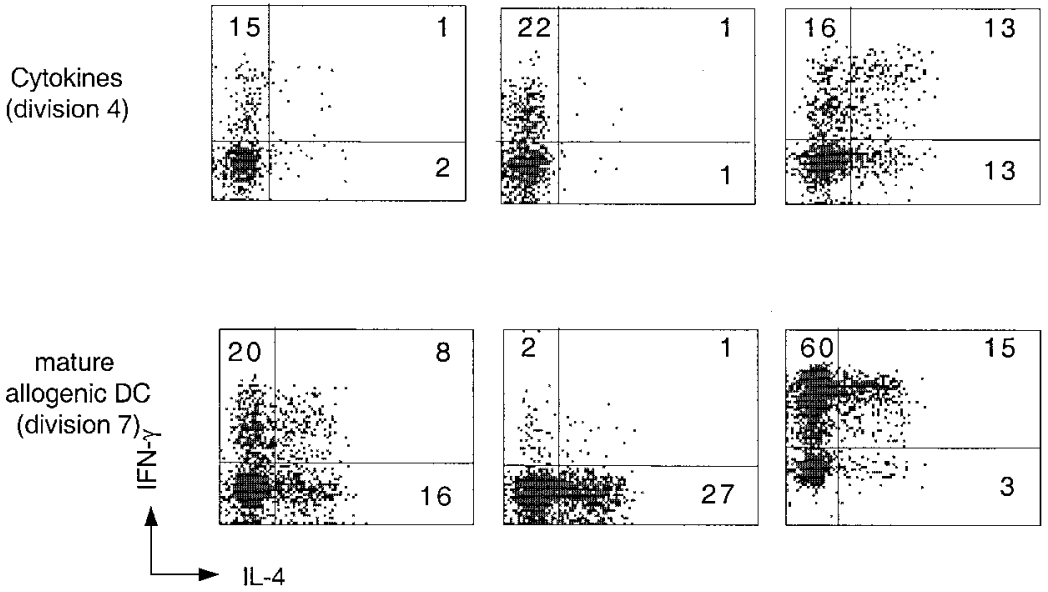

Figure 6. Cytokine-driven differentiation of naive $\mathrm{T}$ and $\mathrm{T}_{\mathrm{CM}}$ cells. (A) CFSE-labeled $\mathrm{CD}^{+}$naive $\mathrm{T}$ and $\mathrm{T}_{C M}$ cells were stimulated with TSST-pulsed DCs or with cytokines (IL-7, IL-15, TNF- $\alpha$, IL-6, and IL-10) for $7 \mathrm{~d}$. Intracellular IFN- $\gamma$ and IL-4 were measured $6 \mathrm{~h}$ after stimulation with PMA and ionomycin. Numbers indicate the percentage of cytokine-producing cells. (B) CFSE-labeled CD4 ${ }^{+}$naive $\mathrm{T}$ cells were stimulated with allogeneic DCs or with cytokines (IL-7, IL-15, TNF- $\alpha$, IL-6, and IL-10) for $7 \mathrm{~d}$ in the absence of IL-4 and IL-12 or in the presence of either IL- 4 and anti-IL-12 or IL-12 and anti-IL4. IFN- $\gamma$ and IL-4 production were measured $6 \mathrm{~h}$ after stimulation with PMA and ionomycin. The dot plots display cells, which had undergone the same number of divisions. One representative experiment out of six.
$(44,45)$, thus inducing proliferation of naive $\mathrm{T}$ cells and boosting that of memory $\mathrm{T}$ cells in response to $\gamma \mathrm{c}$-cytokines. These findings suggest that DCs may play a dual role in promoting both antigen-driven as well as homeostatic $\mathrm{T}$ cell proliferation.

Several studies demonstrated a role for TCR tickling by self-MHC molecules in promoting both survival of naive $\mathrm{T}$ cell under steady-state conditions and their expansion and differentiation in lymphopenic mice $(9-15,46)$. This mechanism, however, is influenced by the capacity of each TCR to interact with self-MHC molecules (17) and would inevitably lead to a skewing of the TCR repertoire. In contrast, cytokine-driven proliferation can be induced and tuned in the absence of TCR stimulation and represents a driving force for the maintenance and expansion of a polyclonal repertoire. In both cases the level of stimulation will depend on $\mathrm{T}$ cell density and competition for access to DCs providing either self-MHC molecules or cytokines.

Previous studies demonstrated that $\gamma c$-cytokines play nonredundant roles in $\mathrm{T}$ cell homeostasis in mice (26-30).
We found that cytokine responsiveness and cytokine receptor expression vary with the differentiation stage of $\mathrm{T}$ cells. The responsiveness to IL-7 and IL-15 and the expression of the IL-2/15R $\beta$-chain are progressively acquired as naive $T$ cells differentiate to $T_{C M}$ and $T_{E M}$. While IL-7 acts synergistically with IL-15 on all CD4 ${ }^{+} \mathrm{T}$ cell subsets, only $\mathrm{T}_{\mathrm{EM}}$ can directly proliferate in response to these cytokines, as naive and $\mathrm{T}_{\mathrm{CM}}$ require $\mathrm{DCs}$ or DC-derived cytokines to upregulate the relevant receptors. In contrast to other $\gamma \mathrm{c}-$ cytokines, IL-4 is selective for naive T cells, an effect that can be explained by the upregulation of the IL- $4 \mathrm{R} \alpha$ chain by IL-4 on naive but not on memory T cells. Altogether these results reveal that $\gamma$ c-cytokine receptor expression is regulated both developmentally and by signals from TCR or DC-derived cytokines.

TCR- and cytokine-driven proliferation can be differentially blocked by inhibitors that selectively target signal transduction pathways. While TCR-driven proliferation is inhibited by CsA and PP2, cytokine-driven proliferation is completely resistant. Furthermore, the p38 pathway is acti- 
vated in response to both TCR and cytokines stimulation, although through different mechanisms. However, pharmacolocical inhibition experiments indicate that p38 is essential for cytokine-driven, but not for TCR-driven proliferation. The reciprocal applies to ERK MAP kinases, which are activated by both stimuli, but are essential only for TCR-induced responses. Our results suggest an essential role for $\mathrm{p} 38$, besides its effects on cytokine production $(47,48)$, in antigen-independent $\mathrm{T}$ cell proliferation.

Cytokine-driven proliferation of human $\mathrm{T}$ cells in vitro can also lead to differentiation. Our study has revealed a striking difference in the differentiation capacity of naive $\mathrm{T}$ versus $T_{C M}$ cells. While cytokine-expanded naive $T$ cells retain a lymph node homing phenotype $\left(\mathrm{CD} 45 \mathrm{RA}^{+}\right.$, $\mathrm{CCR}^{+}$) and undergo only a very limited differentiation, $\mathrm{T}_{\mathrm{CM}}$ differentiate efficiently, losing CCR7 and acquiring CCR 5 as well as the capacity to produce high levels of IFN- $\gamma$ and IL-4, comparable to those produced by effector $T$ cells. These findings indicate that $T_{C M}$ can generate cells with the characteristics of $\mathrm{T}_{\mathrm{EM}}$ in an antigen-independent fashion.

IL-12 is produced by DCs and was recently reported to enhance homeostatic $\mathrm{T}$ cell proliferation in mice (49). The polarizing effects of IL-12 and IL-4 in cytokine driven cultures were unexpected, since IL-12 boosted IFN- $\gamma$ as well as IL-4 producing capacity, while IL-4 boosted only IFN- $\gamma$ production. While the paradoxical Th1 polarizing capacity of IL-4 remains to be explained, its failure to induce Th2 polarization in this system is consistent with previous reports indicating that Th2 polarization critically depends on simultaneous TCR and IL-4R stimulation $(50,51)$

Altogether our results suggest that $T_{C M}$ cells might not only self-renew, but also replenish the $\mathrm{T}_{\mathrm{EM}}$ pool. Indeed, although $\mathrm{T}_{\mathrm{EM}}$ cells are responsive to cytokines they may be consumed as they enter peripheral tissues. Consistent with this hypothesis is the fact that $\mathrm{T}_{\mathrm{CM}}$ incorporate BrdU ex vivo almost as efficiently as $T_{\mathrm{EM}}$, which on the other hand have an enhanced rate of apoptosis (unpublished data). Furthermore the high propensity of $\mathrm{T}_{\mathrm{CM}}$ to undergo terminal differentiation suggests that at least some of the proliferating $\mathrm{T}_{\mathrm{EM}}$ may be generated by homeostatic proliferation and differentiation of the $\mathrm{T}_{\mathrm{CM}}$ pool. Under pathological conditions, the rapid and extensive cytokine-driven differentiation of $\mathrm{T}_{\mathrm{CM}}$ may induce large numbers of effector cells that may damage sensitive target organs such as the gut (52). Altogether these results provide a plausible mechanism for the maintenance of a polyclonal repertoire of memory $T$ cells and for the generation of $\mathrm{T}_{\mathrm{EM}}$ in the absence of antigen from a $\mathrm{T}_{\mathrm{CM}}$ pool.

We thank S. Campagnaro for dedicated help, D. Jarrossay for cell sorting, G. Bosshard for technical assistance, and A. Gett and G. Natoli for critical reading and comments.

This work has been in part supported by the European Community (contract no. QLK2-CT-201-0105). A. Lanzavecchia is supported by the Helmut Horten Foundation and by the Swiss National Science Foundation (grant no. 31-63885).
Submitted: 31 August 2001

Revised: 15 October 2001

Accepted: 5 November 2001

\section{References}

1. Freitas, A.A., and B. Rocha. 2000. Population biology of lymphocytes: the flight for survival. Annu. Rev. Immunol. 18: 83-111.

2. Marrack, P., J. Bender, D. Hildeman, M. Jordan, T. Mitchell, M. Murakami, A. Sakamoto, B.C. Schaefer, B. Swanson, and J. Kappler. 2000. Homeostasis of $\alpha / \beta \mathrm{TCR}^{+} \mathrm{T}$ cells. Nat. Immunol. 1:107-112.

3. Goldrath, A.W., and M.J. Bevan. 1999. Selecting and maintaining a diverse T-cell repertoire. Nature. 402:255-262.

4. Tough, D.F., and J. Sprent. 1994. Turnover of naive- and memory-phenotype T cells. J. Exp. Med. 179:1127-1135.

5. Oehen, S., and K. Brduscha-Riem. 1999. Naive cytotoxic T lymphocytes spontaneously acquire effector function in lymphocytopenic recipients: a pitfall for $\mathrm{T}$ cell memory studies? Eur. J. Immunol. 29:608-614.

6. Murali-Krishna, K., and R. Ahmed. 2000. Cutting edge: naive $\mathrm{T}$ cells masquerading as memory cells. J. Immunol. 165: 1733-1737.

7. Goldrath, A.W., L.Y. Bogatzki, and M.J. Bevan. 2000. Naive $\mathrm{T}$ cells transiently acquire a memory-like phenotype during homeostasis-driven proliferation. J. Exp. Med. 192:557-564.

8. Cho, B.K., V.P. Rao, Q. Ge, H.N. Eisen, and J. Chen. 2000. Homeostasis-stimulated proliferation drives naive $\mathrm{T}$ cells to differentiate directly into memory $\mathrm{T}$ cells. J. Exp. Med. 192:549-556.

9. Kirberg, J., A. Berns, and H. von Boehmer. 1997. Peripheral $\mathrm{T}$ cell survival requires continual ligation of the $\mathrm{T}$ cell receptor to major histocompatibility complex-encoded molecules. J. Exp. Med. 186:1269-1275.

10. Brocker, T. 1997. Survival of mature CD4 T lymphocytes is dependent on major histocompatibility complex class IIexpressing dendritic cells. J. Exp. Med. 186:1223-1232.

11. Takeda, S., H.R. Rodewald, H. Arakawa, H. Bluethmann, and T. Shimizu. 1996. MHC class II molecules are not required for survival of newly generated CD4 ${ }^{+} \mathrm{T}$ cells, but affect their long-term life span. Immunity. 5:217-228.

12. Bender, J., T. Mitchell, J. Kappler, and P. Marrack. 1999. $\mathrm{CD}^{+} \mathrm{T}$ cell division in irradiated mice requires peptides distinct from those responsible for thymic selection. J. Exp. Med. 190:367-374.

13. Tanchot, C., F.A. Lemonnier, B. Perarnau, A.A. Freitas, and B. Rocha. 1997. Differential requirements for survival and proliferation of CD8 naive or memory T cells. Science. 276: 2057-2062.

14. Murali-Krishna, K., L.L. Lau, S. Sambhara, F. Lemonnier, J. Altman, and R. Ahmed. 1999. Persistence of memory CD8 $\mathrm{T}$ cells in MHC class I-deficient mice. Science. 286:13771381.

15. Swain, S.L., H. Hu, and G. Huston. 1999. Class II-independent generation of CD4 memory T cells from effectors. Science. 286:1381-1383.

16. Viret, C., F.S. Wong, and C.A. Janeway. 1999. Designing and maintaining the mature TCR repertoire: the continuum of self-peptide:self-MHC complex recognition. Immunity. 10:559-568.

17. Ernst, B., D.S. Lee, J.M. Chang, J. Sprent, and C.D. Surh. 1999. The peptide ligands mediating positive selection in the 
thymus control $\mathrm{T}$ cell survival and homeostatic proliferation in the periphery. Immunity. 11:173-181.

18. Goldrath, A.W., and M.J. Bevan. 1999. Low-affinity ligands for the TCR drive proliferation of mature $\mathrm{CD} 8^{+} \mathrm{T}$ cells in lymphopenic hosts. Immunity. 11:183-190.

19. Dorfman, J.R., I. Stefanova, K. Yasutomo, and R.N. Germain. 2000. CD4 ${ }^{+} \mathrm{T}$ cell survival is not directly linked to self MHC-induced TCR signaling. Nat. Immunol. 1:329-335.

20. Seddon, B., G. Legname, P. Tomlinson, and R. Zamoyska. 2000. Long-term survival but impaired homeostatic proliferation of naive T cells in the absence of p56lck. Science. 290: 127-131.

21. Nakajima, H., E.W. Shores, M. Noguchi, and W.J. Leonard. 1997. The common cytokine receptor $\gamma$ chain plays an essential role in regulating lymphoid homeostasis. J. Exp. Med. 185:189-195.

22. Lantz, O., I. Grandjean, P. Matzinger, and J.P. Di Santo. 2000. $\gamma$ chain required for naive $\mathrm{CD}^{+} \mathrm{T}$ cell survival but not for antigen proliferation. Nat. Immunol. 1:54-58.

23. Unutmaz, D., P. Pileri, and S. Abrignani. 1994. Antigenindependent activation of naive and memory resting $\mathrm{T}$ cells by a cytokine combination. J. Exp. Med. 180:1159-1164.

24. Unutmaz, D., F. Baldoni, and S. Abrignani. 1995. Human naive $\mathrm{T}$ cells activated by cytokines differentiate into a split phenotype with functional features intermediate between naive and memory T cells. Int. Immunol. 7:1417-1424.

25. Kanegane, H., and G. Tosato. 1996. Activation of naive and memory T cells by interleukin-15. Blood. 88:230-235.

26. Zhang, X., S. Sun, I. Hwang, D.F. Tough, and J. Sprent. 1998. Potent and selective stimulation of memory-phenotype $\mathrm{CD}^{+} \mathrm{T}$ cells in vivo by IL-15. Immunity. 8:591-599.

27. Lodolce, J.P., D.L. Boone, S. Chai, R.E. Swain, T. Dassopoulos, S. Trettin, and A. Ma. 1998. IL-15 receptor maintains lymphoid homeostasis by supporting lymphocyte homing and proliferation. Immunity. 9:669-676.

28. Ku, C.C., M. Murakami, A. Sakamoto, J. Kappler, and P. Marrack. 2000. Control of homeostasis of $\mathrm{CD}^{+}$memory T cells by opposing cytokines. Science. 288:675-678.

29. Schluns, K.S., W.C. Kieper, S.C. Jameson, and L. Lefrancois. 2000. Interleukin-7 mediates the homeostasis of naive and memory CD8 T cells in vivo. Nat. Immunol. 1:426-432.

30. Boursalian, T.E., and K. Bottomly. 1999. Survival of naive CD4 T cells: roles of restricting versus selecting MHC class II and cytokine milieu. J. Immunol. 162:3795-3801.

31. Napolitano, L.A., R.M. Grant, S.G. Deeks, D. Schmidt, S.C. De Rosa, L.A. Herzenberg, B.G. Herndier, J. Andersson, and J.M. McCune. 2001. Increased production of IL-7 accompanies HIV-1-mediated T-cell depletion: implications for T-cell homeostasis. Nat. Med. 7:73-79.

32. Mackay, C.R., W.L. Marston, and L. Dudler. 1990. Naive and memory $\mathrm{T}$ cells show distinct pathways of lymphocyte recirculation. J. Exp. Med. 171:801-817.

33. Sallusto, F., D. Lenig, R. Forster, M. Lipp, and A. Lanzavecchia. 1999. Two subsets of memory $\mathrm{T}$ lymphocytes with distinct homing potentials and effector functions. Nature. 401: 708-712.

34. Manjunath, N., P. Shankar, B. Stockton, P.D. Dubey, J. Lieberman, and U.H. von Andrian. 1999. A transgenic mouse model to analyze $\mathrm{CD}^{+}$effector $\mathrm{T}$ cell differentiation in vivo. Proc. Natl. Acad. Sci. USA. 96:13932-13937.

35. Masopust, D., V. Vezys, A.L. Marzo, and L. Lefrancois. 2001. Preferential localization of effector memory cells in nonlymphoid tissue. Science. 291:2413-2417.

36. Reinhardt, R.L., A. Khoruts, R. Merica, T. Zell, and M.K. Jenkins. 2001. Visualizing the generation of memory CD4 T cells in the whole body. Nature. 410:101-105.

37. Iezzi, G., D. Scheidegger, and A. Lanzavecchia. 2001. Migration and function of antigen-primed nonpolarized T lymphocytes in vivo. J. Exp. Med. 193:987-993.

38. Lyons, A.B., and C.R. Parish. 1994. Determination of lymphocyte division by flow cytometry. J. Immunol. Methods. 171:131-137.

39. Kane, L.P., J. Lin, and A. Weiss. 2000. Signal transduction by the TCR for antigen. Curr. Opin. Immunol. 12:242-249.

40. Karnitz, L.M., and R.T. Abraham. 1995. Cytokine receptor signaling mechanisms. Curr. Opin. Immunol. 7:320-326.

41. Perkins, G.R., J. Marvel, and M.K. Collins. 1993. Interleukin 2 activates extracellular signal-regulated protein kinase 2. J. Exp. Med. 178:1429-1434.

42. Hatakeyama, M., T. Kono, N. Kobayashi, A. Kawahara, S.D. Levin, R.M. Perlmutter, and T. Taniguchi. 1991. Interaction of the IL-2 receptor with the src-family kinase p56lck: identification of novel intermolecular association. Science. 252: 1523-1528.

43. Smith, K.A., and D.A. Cantrell. 1985. Interleukin 2 regulates its own receptors. Proc. Natl. Acad. Sci. USA. 82:864-868.

44. Cantrell, D.A., and K.A. Smith. 1983. Transient expression of interleukin 2 receptors. Consequences for $\mathrm{T}$ cell growth. $J$. Exp. Med. 158:1895-1911.

45. Nakarai, T., M.J. Robertson, M. Streuli, Z. Wu, T.L. Ciardelli, K.A. Smith, and J. Ritz. 1994. Interleukin 2 receptor $\gamma$ chain expression on resting and activated lymphoid cells. $J$. Exp. Med. 180:241-251.

46. Dummer, W., B. Ernst, E. LeRoy, D. Lee, and C. Surh. 2001. Autologous regulation of naive $\mathrm{T}$ cell homeostasis within the T cell compartment. J. Immunol. 166:2460-2468.

47. Rincon, M., H. Enslen, J. Raingeaud, M. Recht, T. Zapton, M.S. Su, L.A. Penix, R.J. Davis, and R.A. Flavell. 1998. Interferon- $\gamma$ expression by Th1 effector T cells mediated by the p38 MAP kinase signaling pathway. EMBO J. 17:2817-2829.

48. Lu, H.T., D.D. Yang, M. Wysk, E. Gatti, I. Mellman, R.J. Davis, and R.A. Flavell. 1999. Defective IL-12 production in mitogen-activated protein (MAP) kinase kinase 3 (Mkk3)deficient mice. EMBO J. 18:1845-1857.

49. Kieper, W.C., M. Prlic, C.S. Schmidt, M.F. Mescher, and S.C. Jameson. 2001. IL-12 enhances CD8 T cell homeostatic expansion. J. Immunol. 166:5515-5521.

50. Iezzi, G., E. Scotet, D. Scheidegger, and A. Lanzavecchia. 1999. The interplay between the duration of TCR and cytokine signalling determines T cell polarization. Eur. J. Immunol. 29:4092-4101.

51. Richter, A., M. Lohning, and A. Radbruch. 1999. Instruction for cytokine expression in $\mathrm{T}$ helper lymphocytes in relation to proliferation and cell cycle progression. J. Exp. Med. 190:1439-1450.

52. Groux, H., and F. Powrie. 1999. Regulatory T cells and inflammatory bowel disease. Immunol. Today. 20:442-445. 